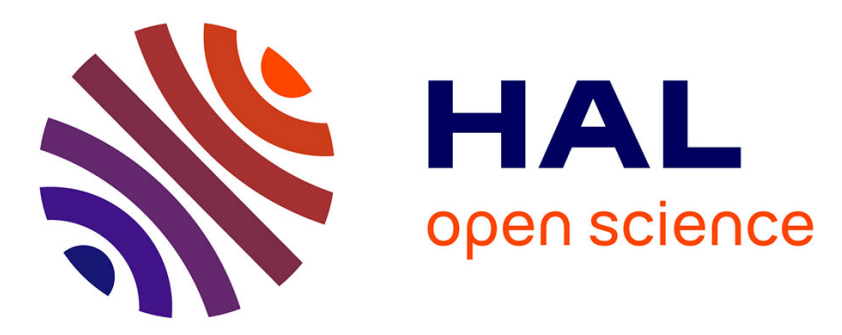

\title{
Relation between the martensite volume fraction and the equivalent transformation strain in shape memory alloys
}

Sylvain Calloch, Karine Lavernhe Taillard, Shabnam Arbab-Chirani, C. Lexcellent, Etienne Patoor

\section{- To cite this version:}

Sylvain Calloch, Karine Lavernhe Taillard, Shabnam Arbab-Chirani, C. Lexcellent, Etienne Patoor. Relation between the martensite volume fraction and the equivalent transformation strain in shape memory alloys. Materials Science and Engineering: A, 2006, 438-440, pp.441-444. 10.1016/j.msea.2005.12.072 . hal-01021408

\section{HAL Id: hal-01021408 \\ https://hal.science/hal-01021408}

Submitted on 9 Jul 2014

HAL is a multi-disciplinary open access archive for the deposit and dissemination of scientific research documents, whether they are published or not. The documents may come from teaching and research institutions in France or abroad, or from public or private research centers.
L'archive ouverte pluridisciplinaire HAL, est destinée au dépôt et à la diffusion de documents scientifiques de niveau recherche, publiés ou non, émanant des établissements d'enseignement et de recherche français ou étrangers, des laboratoires publics ou privés. 


\title{
Relation between the martensite volume fraction and the equivalent transformation strain in shape memory alloys
}

\author{
S. Calloch ${ }^{\mathrm{a}^{*}}$, K. Taillard ${ }^{\mathrm{b}}, \mathrm{S}$. Arbab Chirani ${ }^{\mathrm{c}}$, C. Lexcellent ${ }^{\mathrm{d}}$ and E. Patoor ${ }^{\mathrm{e}}$ \\ ${ }^{a}$ MSN-ENSIETA, Brest, ${ }^{b}$ LMT Cachan, ${ }^{c}$ CERV-ENI Brest, ${ }^{d}$ LMARC Besançon, ${ }^{e}$ LPMM Metz, France
}

\begin{abstract}
This study concerns the pseudoelasticity of SMA. A series of tests under multiaxial loadings and a micro-macro model are used to show the validity of a conjecture concerning the relation between the volume fraction of martensite and the equivalent transformation strain.
\end{abstract}

Key words Superelasticity, Multiaxial Testing, Resistivity, model-experiment dialogue

\section{INTRODUCTION}

Superelasticity is a particular behavior of Shape Memory Alloys (SMA) [1]. It is observed when SMA is mechanically tested at a temperature greater than the $\mathrm{A}_{\mathrm{f}}$ (austenite finish) temperature. In this case, SMA show reversibly hysteretic behavior up to strain levels near $8 \%$. Recently, a macroscopic model which permits to simulate the superelasticity of SMA under complex multiaxial loadings has been proposed [2]. The originality of this model is that, the elastic domain of the material during its two phased state is given by the intersection of two transformation surfaces. The first one permits to control the direct transformation (i.e., austenite _ martensite), and the second one the inverse transformation (i.e., martensite _ austenite). The reorientation mechanism, which is produced just under nonproportional multiaxial loading, is activated when the loading point is situated at the intersection of these two transformation surfaces. None supplementary variable is introduced in the model, the reorientation is modelized (at the adopted description level) by a simultaneous direct and inverse transformation. This model has been validated by a large base of multiaxial testing. Always in this model, a conjecture has been proposed concerning the relation between the equivalent transformation strain and the martensite volume fraction. Up to now, this conjecture has been validated just in the case of an uniaxial tension loading [3]. The objective of the study presented in this paper is to realize a series of tension- torsion proportional testing with the aim of discussing about the validity of the conjecture. The first part of the paper concerns the description of the realized experiments and the obtained results. We can see that a linear relation between the martensite volume fraction and the equivalent transformation strain is really obtained. The proportionality coefficient seems depending on the loading direction. With the aim of analyzing these results, a micromechanical model developed by Patoor et al. $[4,6]$, is used. This more physics model operating as a virtual testing machine permits to discuss the validity of the conjecture.

\section{EXPERIMENTAL RESULTS UNDER MULTIAXIAL LOADING}

The studied material is a polycrystal of $\mathrm{Cu}-\mathrm{Al}-\mathrm{Be}$ SMA. Its composition is $\mathrm{Cu} 87.75 \mathrm{wt} \% \mathrm{Al}$ $11.33 \mathrm{wt} \%$, Be $0.45 \mathrm{wt} \%$. The tension-torsion tubular samples have been machined in the drawn bars then heat treated as the following: heated during 20 minutes at $650{ }^{\circ} \mathrm{C}$ then quenched in bowling water during 1 hour. The four characteristic transformation temperatures have been determined using the resistivity measurement. They are $\mathrm{A}_{\mathrm{s}}=19^{\circ} \mathrm{C}, \mathrm{A}_{\mathrm{f}}=32^{\circ} \mathrm{C}, \mathrm{M}_{\mathrm{s}}=21^{\circ} \mathrm{C}$ and $\mathrm{M}_{\mathrm{f}}=-7^{\circ} \mathrm{C}$.

\subsection{EXPERIMENTAL DETERMINATION OF THE TRANSFORMATION YIELD SURFACE}

A series of experiments under tension (compression)-internal pressure, tension (compression)-torsion and bi-compression loading have been realized with the aim of determining the form of the transformation yield surface of the studied alloy. Detailed information about this study can be found in Bouvet et al. [5]. Just the necessary results are reported in this paper. The figures 1 and 2 show one part of these experimental results. The results of these experiments permitted to define equivalent stresses for isotropic and anisotropic SMA [5]. In the case of an isotropic material, the following equivalent stress has been defined:

$$
\sigma_{\text {eq }}^{\text {iso }}=\sigma_{\text {eq }}^{\text {iso }}\left(\bar{\sigma}, y_{\sigma}\right)=\bar{\sigma} \cdot g\left(y_{\sigma}\right)
$$

* corresponding author 


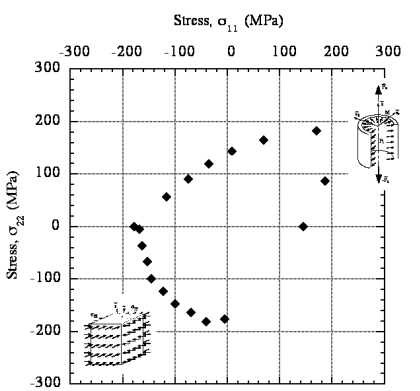

FIG. 1 - Yield Surface in $\left(\sigma_{11}, \sigma_{22}\right)$ plane.

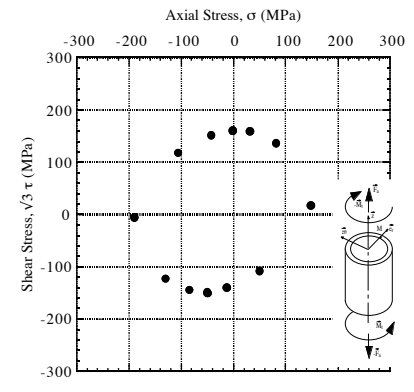

FIG. 2 - Yield Surface in $(\sigma, \tau \sqrt{3})$ plane.

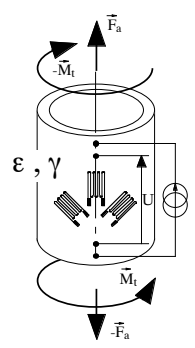

FIG. 3 - Tensiontorsion samples scheme.

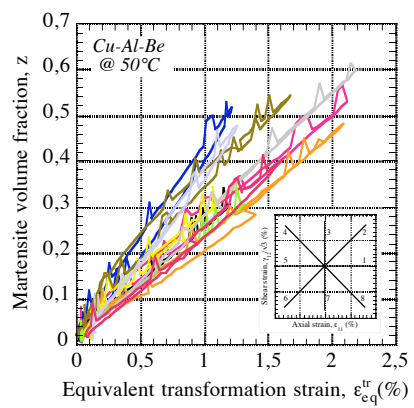

FIG. 4 - Martensite volume fraction $(\mathrm{z})$ evolution with equivalent transformation strain.

where $\bar{\sigma}$ and $y_{\sigma}$ are respectively the equivalent von Mises stress and the third invariant of the stress tensor defined as below:

$$
\bar{\sigma}=\sqrt{\frac{3}{2} \underline{\underline{\sigma}}_{D}: \underline{\underline{\sigma}}_{D}} \quad \text { et } \quad y_{\sigma}=\frac{27}{2} \frac{\operatorname{det}\left(\underline{\underline{\sigma}}_{D}\right)}{\bar{\sigma}^{3}}
$$

and $\mathrm{g}\left(\mathrm{y}_{\sigma}\right)$ is a function defined by relation (3):

$$
\mathrm{g}\left(\mathrm{y}_{\sigma}\right)=\cos \left[\frac{1}{3} \cdot \cos ^{-1}\left(1-\mathrm{a} \cdot\left(1-\mathrm{y}_{\sigma}\right)\right)\right]
$$

where a is a material parameter which can be identified by a compression test.

An equivalent transformation strain can be defined from the equivalent stress definition, the notion of equivalence in the transformation power $\left(\mathrm{P}_{\mathrm{eq}}^{\mathrm{tr}}=\sigma_{\mathrm{eq}} \dot{\dot{\varepsilon}}_{\mathrm{eq}}^{\mathrm{tr}}=\underline{\underline{\sigma}}: \dot{\underline{\varepsilon}}^{\mathrm{tr}}=\mathrm{P}^{\mathrm{tr}}\right)$ and the normality hypothesis $\left(\underline{\underline{\dot{\varepsilon}}}_{\mathrm{tr}}=\dot{\lambda} \frac{\partial \sigma_{\mathrm{eq}}}{\partial \underline{\underline{\sigma}}}\right)$

$$
\varepsilon_{\mathrm{eq}}^{\mathrm{tr}}=\bar{\varepsilon}^{\mathrm{tr}} \cdot \frac{\mathrm{g}\left(-\mathrm{y}_{\varepsilon^{\mathrm{tr}}}\right)}{\mathrm{g}(-1)}
$$

where $\bar{\varepsilon}^{\mathrm{tr}}$ is von Mises equivalent strain $\left(\bar{\varepsilon}^{\mathrm{tr}}=\sqrt{\frac{2}{3} \underline{\underline{\varepsilon}}^{\mathrm{tr}}: \underline{\underline{\varepsilon}}^{\mathrm{tr}}}\right)$ and $\mathrm{y}_{\varepsilon^{\mathrm{tr}}}$ is the third invariant of the transformation strain tensor defined as following:

$$
\mathrm{y}_{\varepsilon^{\mathrm{tr}}}=4 \frac{\operatorname{det}\left(\underline{\underline{\varepsilon}}^{\mathrm{tr}}\right)}{\left(\bar{\varepsilon}^{\mathrm{tr}}\right)^{3}}
$$

\subsection{RELATION BETWEEN THE VOLUME FRACTION OF MARTENSITE AND THE EQUIVALENT TRANSFORMATION STRAIN}

A great number of authors have proposed a linear relation between the martensite volume fraction, $\mathrm{z}$, and the transformation strain in the case of the uniaxial tension [3], [13]. We propose to generalize this relation to the all multiaxial proportional loading paths with the help of the relation (6):

$$
\varepsilon_{\mathrm{eq}}^{\mathrm{tr}}=\gamma \cdot \mathrm{z}
$$

where $\gamma$ is a material parameter.

A series of tests under tension (compression)-torsion loading using tubular samples have been realized to verify the relation (6). During each proportional loading path, the martensite volume fraction and the equivalent transformation strain have been determined respectively by the resistivity and the strain measurement. The figure 3 shows the instrumentation of the tension-torsion samples schematically. The figure 4 shows the volume fraction evolution with the equivalent transformation strain measured during the 8 proportional tests realized in $\left(\varepsilon_{11}, \gamma / \sqrt{3}\right)$ plane. On this figure it can be mentioned that until the tested level of strain, the martensite volume fraction seems to vary linearly with the equivalent transformation strain. On the other hand, the slope of this linear relation seems depending on the loading 
path. With the aim of analyzing these results, the Patoor et al. [4] micromechanical model will be used in the continuation of this work.

\section{MICROMECHANICAL MODEL}

It is based on the self consistent scale transition method [6]. The representative elementary volume is defined at the polycrysal level. Loading is calculated at grain scale using the localization tensor. Considering the local loading state, the martensite activable variants are detected and the volume fraction of each variant and also the induced transformation strain are evaluated. This operation is realized for all the grains of the polycrystal. After determination of the behavior of all the grains, the macroscopic behavior of the SMA is calculated using the average operations.

The data of this model are the crystallographic texture, the transformation temperatures, the material coefficients identified from the state diagram of the SMA, the normal of habit planes and the transformation directions of the 24 variants. At least an interaction matrix which defines two types of interaction (weak and strong) between the formed martensite variants in a grain. All these parameters are physical. They do not depend on the past of the material, except the crystallographic texture.

The crystallographic texture describing the different grains orientation permits to take into account the isotropy or anisotropy of the material related to the forming process [9]. It is well known that the initial crystallographic texture is an important parameter in the behavior of SMA: Bhattacharya [10], Gall [11]. Using the micromechanical model permits to follow the microstructure evolution during loading and to have an idea about the martensite volume fraction level at different scale.

The studied material is a CuAlBe alloy with the macroscopic characteristics described before. In these alloys which are more stable comparing to the other copper based alloys, there are 24 martensite variants forming 6 auto accommodating groups. They are characterized by the normal to the habit plane and the transformation direction. They are the [lll 114 type [12]. The transformation strain amplitude, $g$, is the same for all the variants and it is about 0.23 . The parameters of the interaction matrix are: $50 \mathrm{MPa}$ describing the weak interaction and $260 \mathrm{MPa}$ for the strong one [4]. The appearance of the martensitic transformation is related to the chemical potential $\Delta \mathrm{G}$ which has a linear form around the $M_{s}$ temperature:

$$
\Delta \mathrm{G}_{\mathrm{ch}}=\mathrm{B}\left(\mathrm{T}-\mathrm{M}_{\mathrm{s}}\right)
$$

The parameter $\mathrm{B}$ value is $0.23 \mathrm{MPa} / \mathrm{K}$ in equation (7) [4]. The elasticity is supposed to be isotropic and the same in the two phases.

In the following part, the micromechanical model is used with the aim of validating the shape of the transformation surfaces obtained by the macroscopic model and discussing the validity of the relation between the martensite volume fraction and the equivalent transformation strain. All the simulations, realized using the micromechanical model, are obtained from an isotropic polycrystal containing 1000 grains.

\subsection{TRANSFORMATION SURFACES}

The figure 5 and 6 show the comparison between the transformation surfaces in the $\left(\sigma_{11}, \sigma_{22}\right)$ and $\left(\sigma_{11}, \tau\right)$ planes calculated by the micromechanical and the macroscopic model. A good agreement between the two models is observed.

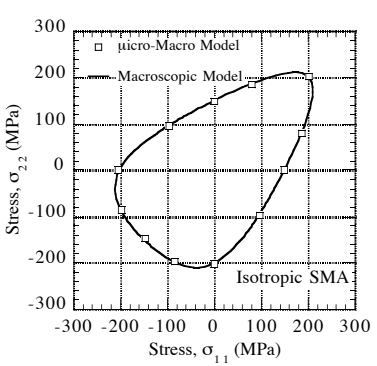

FIG. 5-Transformation surface in $\left(\sigma_{11}, \sigma_{22}\right)$ plane.

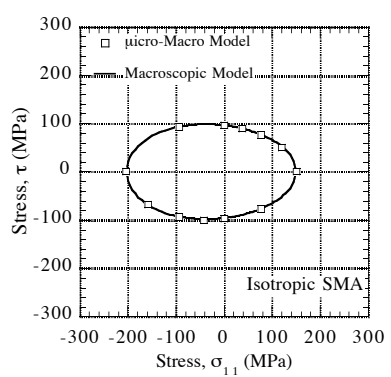

FIG. 6 - Transformation surface in $\left(\sigma_{11}, \tau\right)$ plane.

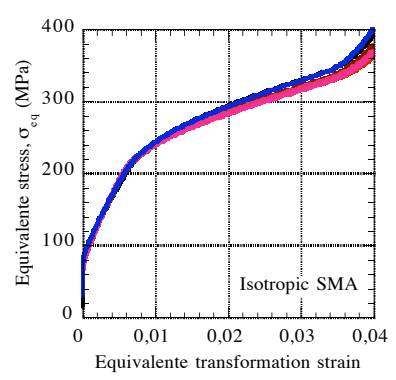

FIG. 7 - Equivalent stress evolution with equivalent transformation strain.

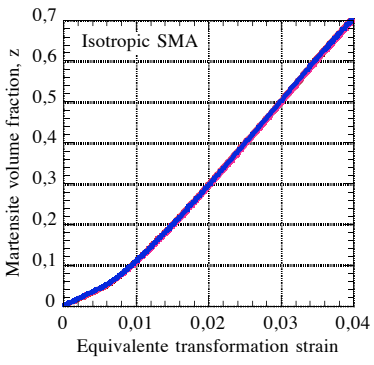

FIG. 8 - Martensite volume fraction evolution with equivalent transf. strain. 


\subsection{RELATION BETWEEN THE MARTENSITE VOLUME FRACTION AND THE EQUIVALENT TRANSFORMATION STRAIN}

The other interesting aspect of the realized simulations concerns the equivalent stress evolution as a function of the equivalent transformation strain and the martensite volume fraction evolution as a function the equivalent transformation strain. The figure 7 and 8 show these evolutions for 8 different proportional loading paths. We can consider that for the all selected loading, the curves giving the equivalent stress as a function of transformation strain are the same. This permits the validation of the defined equivalent stress and transformation strain in the case of isotropic SMA. We can also observe, except for the transformation beginning, that the martensite volume fraction evolution with the equivalent transformation strain is linear. In the case of an isotropic SMA the proportional coefficient does not depend on the considered loading path. The existence of a different slope at the beginning of the transformation had already been observed by Entemeyer [6]. It persists, in the material behavior, until that the transformation phase concerns the majority of the grains.

\section{CONCLUSION}

A testing campaign under tension-torsion loading has been developed with the aim of validation the relation between the martensite volume fraction and the equivalent transformation strain so frequently used in the macroscopic models. The results show that this relation is perfectly linear but the slope seems depending on the loading path. Using micromechanical model of Patoor et al. [4] has permitted the study of these experimental results differently. By this way the equivalent stress and transformation strain definitions have been validated. The conjecture in the case of isotropic SMA has also been verified. The experimental results interpretation is still remained. Taking into account the anistropy of the studied alloy will maybe allow the generalization of the conjecture in the case of anisotropic SMA. Consequently, a new equivalent stress and associated strain should be defined. In this context the micromechanical model will be a real help.

\section{References}

[1] E. Patoor et M. Berveiller, 1990. Les alliages à mémoire de forme, Hermes.

[2] C. Bouvet, S. Calloch et C. Lexcellent, 2004. A phenomenological model for pseudoelasticity of SMA under multiaxial proportional and nonproportional loadings", Eur. J. Mech. , A/Solids, 23, 37-61.

[3] P. Vacher et C. Lexcellent, 1991. Study of pseudoelastic behavior of polycrystalline SMA by resistivity measurements and acoustic emission, Proc. of ICM VI, 6, 231-236.

[4] E. Patoor et M. Berveiller, 1997. Micromechanical modeling of thermoelastic behavior of shape memory alloys, in CISM lecture notes $n^{\circ} 368$ Mechanics of Solids with phase change, edited by F. D. Fischer and M. Berveiller, 121-188.

[5] C. Bouvet, S. Calloch et C. Lexcellent, 2002. Mechanical behavior of a Cu-Al-Be SMA under multiaxial proportional and nonproportional loadings, J. Eng. Mat. Techn., 124, 112-124.

[6] D. Entemeyer,1996. Etude micromécanique du comportement thermomécanique des alliages à mémoire de forme, Thèse de doctorat, Université de Metz.

[7] M. Berveiller et A. Zaoui, 1984. Modelling of the plastic behavior of inhomogeneous media, J. Eng. Mat. and Tech., 106, 295-299.

[8] N. Siredey, E. Patoor, M. Berveiller et A. Eberhardt,1999. Constitutive equations for polycrystalline thermoelastic shape memory alloys. Part I. Intragranulaire interactions and behavior of the grain, Int. J. of Solids and Structures, 36, 4289-4315.

[9] S. Arbab Chirani, D. Aleong, C. Dumont, D. McDowell et E. Patoor, 2003. Superelastic behaviour modelling in shape memory alloys, J. Phys. IV, 112, 205-208.

[10] K. Bhattacharya, K., et R.V. Koh, 1996. Symmetry, Texture and the Recoverable Strain of Shape Memory Polycrystals, Acta mater., 44, No. 2, 529-542.

[11] K. Gall et H. Sehitoglu, 1999. The role of texture in tension-compression asymmetry in polycrystalline NiTi, Int. J. of Plasticity, 15, 69-92.

[12] F. Moreau, 1996. LETAM, Université de Metz, Communication interne.

[13] Q. P. Sun and K. C. Hwang, 1993. Micromechanics modelling for the constitutive behavior of polycrystalline shape memory alloys, J. Mech. Phys. Solids, 41, 1-33. 